\title{
Ontogeny of the pineal melatonin rhythm and implications for reproductive development in domestic ruminants
}

\author{
Steven M. Yellon ${ }^{\mathrm{a}}$, Douglas L. Foster ${ }^{\mathrm{b}}$, Lawrence D. Longo ${ }^{\mathrm{a}}$ and James M. \\ Suttie ${ }^{\mathrm{c}}$

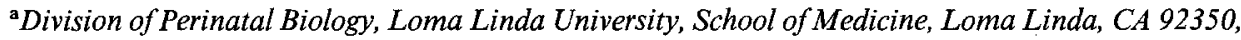 \\ USA \\ ${ }^{\mathrm{b}}$ Reproductive Science Program, The University of Michigan, Ann Arbor, MI 48109, USA \\ 'Invermay Agricultural Centre, Ministry of Agriculture and Fisheries, Mosgiel, New Zealand
}

\begin{abstract}
Yellon, S.M., Foster, D.L., Longo, L.D. and Suttie, J.M., 1992. Ontogeny of the pineal melatonin rhythm and implications for reproductive development in domestic ruminants. Anim. Reprod. Sci., 30: $91-112$.

This review focuses on the important contribution that domestic ruminants have made to understanding the role of environmental photoperiod in the process of reproductive maturation. Evidence in the sheep, goat and deer indicate that the influence of photoperiod on growth and the onset of puberty is mediated by the pineal gland and secretion of the hormone melatonin. The ontogeny of the circadian melatonin rhythm is discussed in relation to its role in the timing of puberty for these ruminant species.
\end{abstract}

\section{INTRODUCTION}

Environmental factors, such as photoperiod, are now recognized to be of critical importance for the process of sexual maturation in a variety of mammalian species (Foster, 1980; Reiter, 1986). Of special interest is the domestic ruminant, because during the first year of life photoperiod is known to modulate growth (Schanbacher and Crouse, 1980; Abbott et al., 1984; Tucker et al., 1984), as well as the onset of reproductive function in several ruminant species (for review see Foster et al., 1985).

A hallmark characteristic of many domestic ruminants, including sheep, goats, and deer, is that breeding is seasonal, usually restricted to the decreasing days of autumn or the short days of winter (Ortavant et al., 1985). A lack of seasonality in reproduction in certain species of ruminants (Bissonnette, 1941; Hafez, 1952; Hansen, 1985) does not preclude that hormone secretion and reproductive physiology cannot be influenced by photoperiod. The process of domestication selects traits that are desirable to humans, sometimes at the expense of those that are adaptive to nature. It is important, though,

Correspondence to: S.M. Yellon, Division of Perinatal Biology, Loma Linda University, School of Medicine, Loma Linda, CA 92350, USA.

(C) 1992 Elsevier Science Publishers B.V. All rights reserved 0378-4320/92/ $\$ 05.00$ 
that wild sheep and goats, in particular, have a restricted breeding season, the duration of which depends on the geographical origin of the species (Hafez, 1952). Thus, for many domestic ruminants, mechanism of adaptation to the environment are retained as a link with primitive or wild progenitors of the species.

The effects of photoperiod on reproduction in adult sheep (Bittman and Karsch, 1984), deer (Plotka et al., 1982), and goat (Hansen, 1985; Maeda et al., 1988) depend upon the pineal gland, and its secretion of the hormone, melatonin. The circadian melatonin rhythm provides a critical endocrine signal to regulate secretion of other hormones involved in the onset and termination of the annual breeding season. The following review will focus on reproductive development and the important contributions of domestic ruminants for understanding the photoperiodic mechanism in the process of puberty. The ontogeny of the circadian melatonin rhythm and its role in timing puberty will also be discussed. The female lamb, in particular, has served as a valuable animal model to unravel how changes in photoperiod during development can advance or delay the normal timing of puberty. Thus the emphasis on the sheep model is based on an increasing volume of literature; pertinent data will be referenced for other species, however.

\section{THE NEUROENDOCRINE BASIS FOR REPRODUCTIVE DEVELOPMENT}

Physiological change characterizes the process of puberty. The complex mechanism timing the transition into adulthood reflects the existence of diverse physiological components, all of which simultaneously proceed towards the attainment of reproductive competence. Of the many overt signs of puberty, first ovulation has been considered as the time of puberty in the female lamb. This first of a series of repetitive cycles in the lamb resembles the follicular phase of the adult ovarian cycle (Foster et al., 1986), and is similar to the endocrine changes associated with the onset of breeding for adult sheep (Karsch et al., 1984).

The hormonal changes associated with puberty in the lamb have been extensively reviewed (Foster, 1988; Foster et al., 1985, 1986), and will only briefly be considered here. In the female lamb, increased frequency of pulsatile luteinizing hormone ( $\mathrm{LH}$ ) secretion, presumably driven by the hypothalamic gonadotrophin-releasing hormone $(\mathrm{GnRH})$, along with sufficient concentrations of follicle-stimulating hormone (FSH) in circulation, stimulate estrogen production by the maturing preovulatory follicle. Driven by the higher LH pulse frequency, the increase in circulating estrogen produces a massive surge in pituitary gonadotrophins ( $\mathrm{LH}$ and FSH), which induces ovulation.

The absence of ovulatory cycles before puberty relates to the pattern of pulsatile LH secretion (Foster and Ryan, 1981). In the sexually immature lamb, 
LH pulse frequency is low and insufficient to drive follicular maturation. Highfrequency LH pulses, typical of the follicular phase, can be elicited within a few weeks after birth by removal of the ovaries. Thus, the lamb has the ability to produce high-frequency GnRH secretion long before puberty, but this increased drive of gonadotrophins is not expressed. Moreover, the ovary and pituitary are capable of adult-like function from an early age, because, under experimental conditions, the immature lamb can produce ovulatory follicles and respond to the positive feedback action of estrogen with a true surge in gonadotrophin hormones.

What forestalls the expression of the high LH pulse frequency (follicular phase) until the pubertal transition is that the neuroendocrine mechanism controlling GnRH secretion is exquisitely sensitive to estrogen inhibitory feedback. Experimentally, doses of exogenous estradiol that suppress pulsatile $\mathrm{LH}$ release in sexually immature lambs are unable to affect $\mathrm{LH}$ secretion after puberty. Therefore, puberty occurs in response to reduced feedback sensitivity of the GnRH pulse generator to estrogen. After puberty, progesterone from the newly formed corpus luteum becomes the principal ovarian steroid in the feedback control of GnRH pulse frequency during the ovulatory cycle of the sheep (Karsch et al., 1984).

For the adult female sheep, day length is the major environmental variable governing seasonal reproduction (see Karsch et al., 1984). Under natural conditions, the breeding season begins when day length is decreasing and ends after the winter solstice, when day length is increasing. The reproductive response to photoperiod is mediated by the pineal gland through its circadian pattern of melatonin secretion. This response to photoperiod affects the neuroendocrine system because day length is positively correlated with sensitivity of the LH secretory system to the inhibitory feedback action of estrogen, and inversely related to LH pulse frequency. The effects of photoperiod on both the feedback action of estrogen and the regulation of pulsatile $\mathrm{LH}$ secretion are mimicked by appropriate timed treatments with melatonin (Bittman et al., 1985). For the discussion of photoperiod control of reproduction, the role of the pineal gland and its hormone, melatonin, are of prominent importance.

\section{THE PINEAL MELATONIN RHYTHM}

The pineal gland synthesizes a variety of hormones and indoleamines, of which melatonin has been extensively studied (Sugden, 1989). In most mammals, the pineal gland primarily, if not exclusively, accounts for the $24 \mathrm{~h}$ pattern of melatonin in circulation (for review see Hastings et al., 1989). The melatonin secretion pattern is known as a circadian rhythm because the rise and fall of melatonin concentrations in circulation has a periodicity of about $24 \mathrm{~h}$ that persists in constant darkness (sheep: Rollag and Niswender, 1976; 
Djungarian hamster: Yellon et al., 1982). The circadian melatonin rhythm can be eliminated by exposure to constant light (Namboodiri et al., 1985), pinealectomy (Bittman and Karsch, 1984), or superior cervical ganglionectomy, i.e. destruction of the neural pathway that innervates the pineal gland (Yellon and Foster, 1986).

Of particular importance for pineal melatonin synthesis are the suprachiasmatic nuclei, a bilateral cluster of neurons in the anterior hypothalamus which, through a multisynaptic pathway, controls pineal melatonin production (reviewed by Rusak and Zucker, 1979; Karsch et al., 1984). In rodents, the suprachiasmatic nuclei are considered a biological clock for two reasons. First, the neurons within this brain region maintain a $24 \mathrm{~h}$ rhythm in activity in constant light conditions (Schwartz et al., 1980). Second, these neurons are involved in the mechanism generating a variety of other circadian rhythms (Rusak and Zucker, 1979). The activity of neurons in the suprachiasmatic nuclei is entrained to a precise $24 \mathrm{~h}$ pattern by light cues. Although comparable studies have yet to be performed in ruminants, in both rats and sheep photoperiod cues are solely recognized by photoreceptors in the retina which convey information about light to the suprachiasmatic nuclei (see Legan and Winans, 1981). Therefore, the ability of photoperiod to entrain the circadian activity of neurons in the suprachiasmatic nuclei provides the mechanism through which photoperiod regulates the pineal melatonin rhythm.

How the pineal gland acts to transduce photoperiodic information depends upon characteristics of the rhythm in melatonin production (Fig. 1). In the post-pubertal lamb, melatonin in circulation increases within a few hours after darkness from low daytime levels (Yellon and Foster, 1986; Claypool et al., 1989). Melatonin concentrations remain elevated for the duration of the night and, in anticipation of the onset of light, fall to low daytime levels. This description of the melatonin rhythm holds whether lambs are in long days or short days, except that the duration of elevated circulating melatonin is directly proportional to the hours of darkness. It has yet to be determined whether the rise, peak, fall, or phase coincidence of the melatonin rhythm with another circadian rhythm is biologically relevant (Wayne et al., 1988, p. 72). However, studies with timed infusions of melatonin in the lamb clearly demonstrate that the duration of increased circulating melatonin conveys information about day length, and that this information is used to control the onset of puberty (Yellon and Foster, 1986; Ebling et al., 1988). In other ruminants as well, melatonin rhythms that are appropriate to day length and comparable to those in sheep have been found for deer (Bubenik and Smith, 1987), goats and cattle (Kennaway, 1984). For the developing ruminant (Foster et al., 1986), as already mentioned for the adult female sheep (Karsch et al., 1984), the importance of the melatonin rhythm for reproduction can only be fully appreciated by understanding the photoperiodic cues required for puberty. 


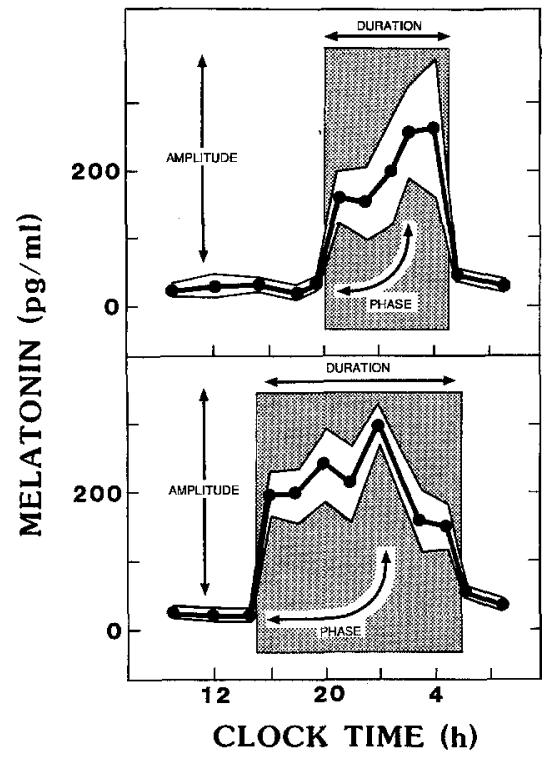

Fig. 1. Serum melatonin concentrations in post-pubertal lambs reared in long days (top: $15 \mathrm{~h}$ of light each day, lights-on 05:00 h; n=6) or short days (bottom: $9 \mathrm{~h}$ of light each day, lights-on $06: 00 \mathrm{~h} ; n=4)$. Shaded areas represent dark periods. Three circadian characteristics of the melatonin rhythm are noted: duration (hours of sustained increase in circulation compared with daytime baseline), amplitude (day/night difference), and phase (temporal relation between peak and baseline or between melatonin and some other rhythm). (Modified from Foster et al., 1985).

\section{PHOTOPERIOD TIMING OF REPRODUCTIVE DEVELOPMENT}

Lambs are typically born from late winter through early spring, and attain puberty in the autumn at about 30 weeks of age (Fig. 2) (Foster and Ryan, 1981). Lambs born out of season, in autumn, delay puberty to the following autumn when they are about 1 year of age, which coincides with the normal breeding season (Foster, 1981). Comparisons between spring-born and autumn-born lambs lead to the conclusion that chronological age or body size provide cues for puberty which are often secondary to that of photoperiod (issues concerning growth are discussed later). Even photoperiod control of reproductive cyclicity is not absolute because exposure of a female lamb to a ram can advance the age of puberty in the presence of typically inhibitory day lengths (Oldham and Gray, 1984). Therefore, in the hierarchy of internal and external cues which can affect reproductive development (Foster et al., 1985 ), photoperiod plays a dominant role in timing of puberty in the female sheep.

Abundant evidence in the female lamb indicates that postnatal photoperiod history provides crucial information to initiate reproductive cycles. The 


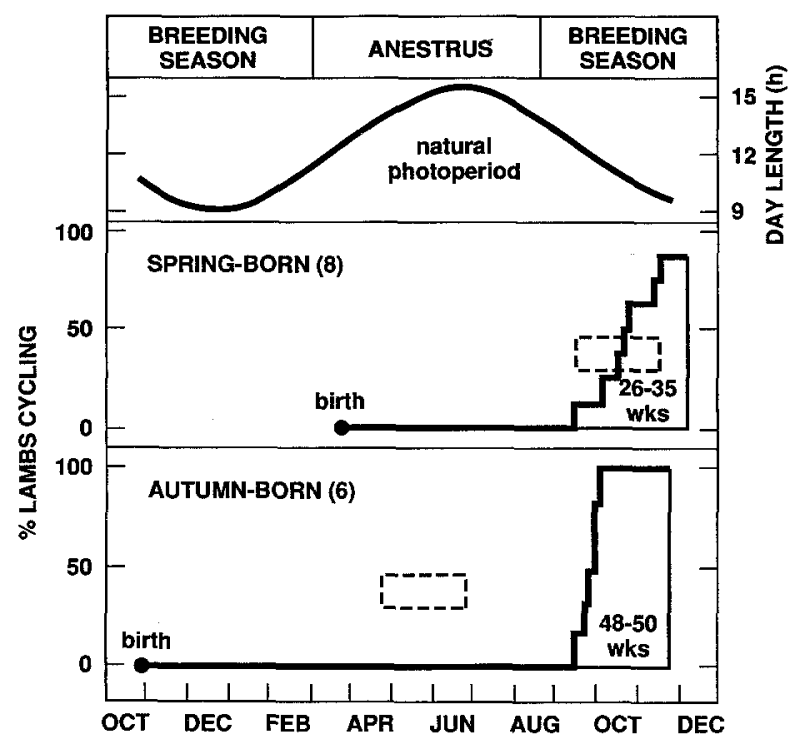

Fig. 2. Onset of reproductive cycles in lambs in natural photoperiod: spring-born $(n=8)$ or autumn-born $(n=6)$. Periods of breeding and anestrus in the annual seasonal cycle of adult sheep are indicated at top. Dashed box indicates normal chronological age for puberty. (Modified from Foster and Ryan, 1981).

normal onset of ovarian cycles requires no more than 5 weeks exposure to long days, a period comparable to the peak in day length that occurs around the summer solstice (Yellon and Foster, 1985). Either the continuous presence of long days from soon after birth, or the absence of long days, as in continuous short days, delays puberty well beyond the normal time of 30 weeks of age (Fig. 3). It should be noted that most photoperiods are not absolutely stimulatory or inhibitory in the adult sheep, since the effect of a photoperiod treatment on reproduction depends, in part, on previous day length (Robinson and Karsch, 1987). This ability to respond to relative changes in day length, rather than absolute day lengths, has thus far been demonstrated for the lamb as well, at least in the case of prolactin secretion (Ebling et al., 1989). Similarly, for the lamb as in the adult, long days are not strictly inhibitory nor are short days solely stimulatory for reproductive function (Yellon and Foster, 1985). During development, a change in photoperiod, requiring some long days, is needed for the normal timing of puberty.

Important characteristics of the long-day requirements to initiate reproductive cycles have been defined by exposure of lambs to periods of artificial long and short days of varying weeks duration at different chronological ages during development (Yellon and Foster, 1985). Repetitive ovulatory cycles are initiated when lambs are exposed to long days between 17 and 22 weeks of age. As little as 1 week of long days (Week 21) can fulfill this requirement 


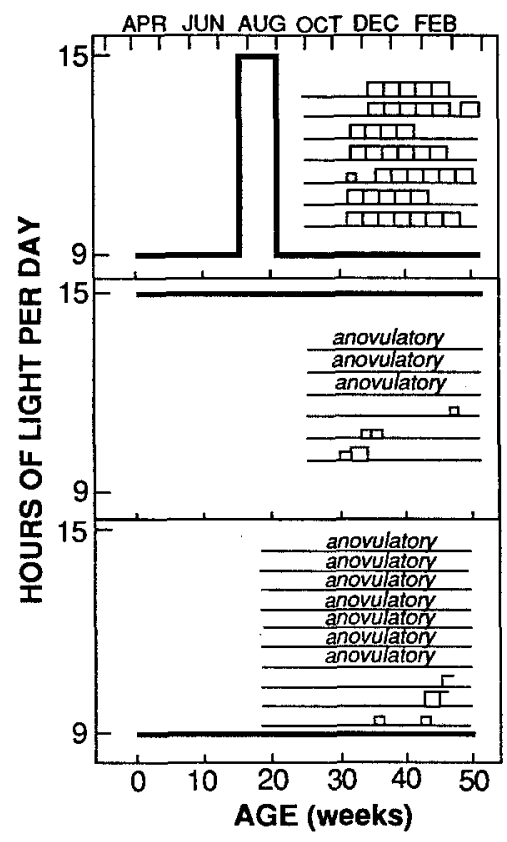

Fig. 3. Photoperiod requirements for normal timing of puberty in female spring-born lambs. Lambs were reared in artificial photoperiod (dark line). Top: 5 weeks of long days ( $15 \mathrm{~h}$ of light each day) preceded and followed by short days ( $9 \mathrm{~h}$ of light each day); Middle: long days; Bottom: short days. For each individual lamb; data are indicated by large and small blocks which represent normal and short luteal phase cycles, respectively. (From Yellon and Foster, 1985 ).

for long days. However, the higher frequency of aberrant short luteal phase cycles following only 1 week of long days suggests that there is a lower limit to the number of long days needed for normal puberty. Moreover, short days are not needed prior to this block of long days because lambs reared in long days until 22 weeks, followed by short days thereafter, initiate reproductive cycles by 30 weeks of age (Foster et al., 1988c).

In contrast to the dramatic onset of ovarian cycles which defines puberty in the female lamb, the pubertal transition in the male is much less remarkable and appears to be more independent of photoperiod. Testicular growth at the onset of puberty, before 17 weeks of age, was not found to be influenced by photoperiod (Claypool, 1985) or melatonin treatments (Kennaway and Gilmore, 1985) that are known to block puberty in females. Similarly, and in marked contrast to the female, the inhibitory feedback action of estradiol on LH secretion was only transiently influenced by length of day during the first 17 weeks after birth in the male lamb (Claypool and Foster, 1990; Wood et 
al., 1991 ). Although male reproductive development appears not to be strongly influenced by photoperiod, light cues do regulate melatonin and prolactin secretion in males, much as in female lambs (Claypool et al., 1989; Ebling et al., 1989). Thus, the developing male sheep is photoperiodic to the extent that certain patterns of hormone secretion are modulated by length of day, but mechanisms driving the maturation of reproductive function are less responsive to such alterations in light.

\section{THE PINEAL GLAND AND REPRODUCTIVE DEVELOPMENT}

Further support for the importance of long days for initiating puberty in female lambs comes from studies that reveal a role for the pineal gland in reproductive development. The pineal gland has for some time been implicated in the timing of puberty (for review see Reiter, 1986). A clear role for the pineal gland in reproductive development has been established in only a limited number of species, those that are sensitive to photoperiod during sexual maturation, e.g. sheep and Djungarian hamsters (Ebling and Foster, 1989 ). In the young lamb, removal of the pineal gland delays the onset of reproduction (Kennaway et al., 1985). Denervation of the pineal by superior cervical ganglionectomy also delays puberty (Yellon and Foster, 1986; Foster et al., 1988a,b) (Fig. 4, third panel). However, to inhibit the normal onset of ovulatory cycles ganglionectomy must occur before long-day exposure (1722 weeks of age ). Presumably abolishing the pineal melatonin rhythm at an early age delays puberty because the physiological signal that conveys information about long days is lacking. By contrast, ganglionectomy at 22 weeks of age, after 5 weeks of long days, leads to the normal onset of puberty (Fig. 4 , second panel). Even though these lambs remained in long days, the onset of repetitive cycles underscores that after pineal denervation, recognition of photoperiod cues does not occur in the absence of a circadian melatonin rhythm.

The above findings support two important hypotheses concerning seasonal puberty in the lamb. First, the female lamb must experience long days followed by the removal of long-day cues to initiate reproductive cycles. Second, the pineal gland mediates this information about the photoperiodic history to time puberty. As stated, these hypotheses also apply to findings in other ruminant species. In adult deer, pinealectomy disrupts the normal timing of seasonal rhythms in prolactin, antler growth, body weight, and moulting (Plotka et al., 1982). While seasonal variation in plasma prolactin is abolished in mature goats by ganglionectomy (Buttle, 1977), in both deer and goats photoperiod is known to regulate reproductive function (Plotka et al., 1982; More et al., 1984). Although not yet known for the goat, there is some suggestion of a role for the pineal gland in reproductive development in the deer. Prepubertal deer exposed to short days exhibited advance puberty in 


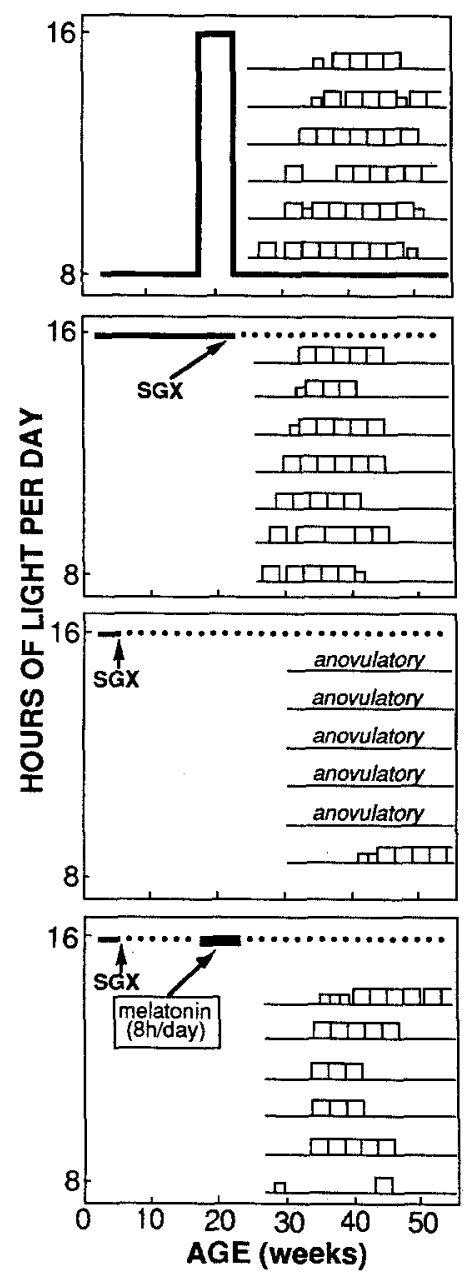

Fig. 4. Pineal melatonin requirements for the normal timing of puberty in the lamb. Lambs were reared in artificial photoperiod (dark or dotted line). Top panel: the control group (six lambs) experienced short days ( $8 \mathrm{~h}$ of light each day) before and after the 5 week block of long days ( $16 \mathrm{~h}$ of light each day). Bottom three panels: lambs were reared solely in long days and, in each animal, the pineal gland was denervated by superior cervical ganglionectomy (SGX) at age 23 weeks (second panel, seven lambs) or at 3-4 weeks (third and bottom panels, six and five lambs, respectively). Bottom panel: lambs were infused each night with melatonin for ( $8 \mathrm{~h}$ day $^{-1}$ ) 5 weeks (dark bar, 18-23 weeks of age). Normal or short luteal phase cycles in each individual are represented by large or small blocks, respectively (Redrawn from Foster et al., 1988b).

terms of premature onset of reproductive activity, reduced circulating prolactin, and pelage moult (Webster and Barrell, 1985). 
Simply stated, the duration of the night-time rise in circulating melatonin is proposed to relay information about photoperiod to the neural mechanisms timing puberty in the female lamb. This hypothesis is based, in part, on investigations in the adult ewe (Bittman and Karsch, 1984; Yellon et al., 1985b), and on studies in which lambs with denervated pineal glands were repeatedly infused with melatonin at a specific time of day and duration. Evidence in Fig. 4, and in other studies indicate that pineal denervation before 17 weeks of age delays the onset of ovulatory cycles beyond 30 weeks of age, the normal age for puberty, irrespective of the photoperiod treatment during development (Yellon and Foster, 1986; Foster et al., 1988a,b). Puberty can be restored to the normal age in lambs with a denervated pineal gland by timed infusions of a long-day pattern of melatonin ( $8 \mathrm{~h}$ per night) for a minimum of 5 weeks (before 22 weeks of age), again irrespective of the photoperiod treatment during development (Foster et al., 1988b) (Fig. 4, bottom). Therefore, a relatively brief daily melatonin treatment ( $8 \mathrm{~h}$ infusion) in ganglionectomized lambs mimicked the effects of long days in pineal-intact lambs to time the normal onset of reproductive cycles. The effects of timed melatonin treatments in lambs with a denervated pineal gland are not limited to long-day responses. Melatonin infusions lasting $15 \mathrm{~h}$ each day are likely to simulate short days (Yellon and Foster, 1986), as in the adult ewe (Karsch et al., 1984).

Melatonin infusions that solely supplement the amplitude of the night-time melatonin rise in pineal-intact lambs, i.e. no change in duration, do not alter the typical response to long days (Ebling et al., 1988; Foster et al., 1989). Thus, the available evidence suggests that amplitude of the nightly melatonin rise does not relay any physiological amplitude of the nightly melatonin rise does not relay any physiological information in the lamb (Foster et al, 1989).

No study of the photoperiodic requirement for puberty has adequately tested the hypothesis that it is the phase coincidence of the melatonin rhythm with another circadian rhythm that conveys information about day length. Infusions of melatonin have always been administered to lambs during the night (Yellon and Foster, 1986; Foster et al., 1988a,b). To test the phase hypothesis, timed treatments of melatonin must occur in ganglionectomized or pinealectomized lambs during the daytime. Although not yet done, such experiments may not be necessary. The concept of the duration of the melatonin signal has recently received considerable refinement in adult sheep (Wayne et al., 1988) with the additional requirement that a melatonin duration can facilitate or inhibit reproduction; the direction of the change in duration also carries relevant photoperiodic information (Robinson and Karsch, 1987). LH secretion was increased when ewes were shifted from 16 to $13 \mathrm{~h}$ of light each day, but a photoperiod change from 10 to $13 \mathrm{~h}$ of light each day sup- 
pressed LH in circulation. The concept of direction of change implies that a biological response, e.g. timing of puberty, depends on whether the duration is approached from an increasing or decreasing day length. Therefore, what appears to give the most relevant photoperiodic information is not an absolute photoperiod but a change between photoperiods. At present, it is difficult to incorporate information about direction of photoperiod change into the current formulation of the phase hypothesis (Bartness and Goldman, 1989; Hastings et al., 1989).

In addition, initial studies in the female lamb demonstrated that melatonin implants altered the normal timing of puberty. Constant melatonin release delayed puberty when implants were given early in life (Kennaway and Gilmore, 1984, 1985). Comparable treatment at older ages advanced the age at puberty (Nowak and Rodway, 1985). The effects of continuously elevated melatonin concentrations on puberty are dramatic, but the mechanism is uncertain. The non-physiological pattern of melatonin in circulation may be interpreted as an ambiguous photoperiod cue or even as a constant signal, effectively blocking day-length information.

In summary, the findings indicate that the duration of increased melatonin in circulation can provide physiologically relevant cues to the lamb about both long and short day length. A similar conclusion has been derived from studies in adult sheep (Yellon et al., 1985b; Wayne et al., 1988), and in the prepubertal Djungarian hamster (Goldman et al., 1984; Bartness and Goldman, 1989; Elliot et al., 1989) in which duration of the nocturnal melatonin rhythm transduces information about photoperiod to the neuroendocrine mechanism controlling the reproductive system. Further support for this hypothesis is provided in red deer where oral administration of melatonin late in the afternoon advances puberty (Webster and Barrell, 1985). Even though duration of increased melatonin in circulation seems important, studies are needed to address alternative hypotheses that some photoperiod information may be provided by the internal coincidence of the melatonin rhythm with some other circadian rhythm.

\section{ONTOGENY OF THE PINEAL MELATONIN RHYTHM}

The distinguishing characteristic of a well-established pineal melatonin rhythm in the adult is the ability of photoperiod to entrain circadian melatonin secretion. The Djungarian hamster, for example, is extremely immature at birth (altricial species), and the pineal melatonin rhythm develops between 15 and 20 days after birth (Yellon et al., 1985a), a stage of development coincident with the onset of puberty (Yellon and Goldman, 1984).

For sheep, which are well developed at birth (precocial species), photoperiod-entrained melatonin rhythms are evident in the fetus early in the last third of gestation (Fig. 5, top) (Yellon and Longo, 1987; Zemdegs et al., 1988). 


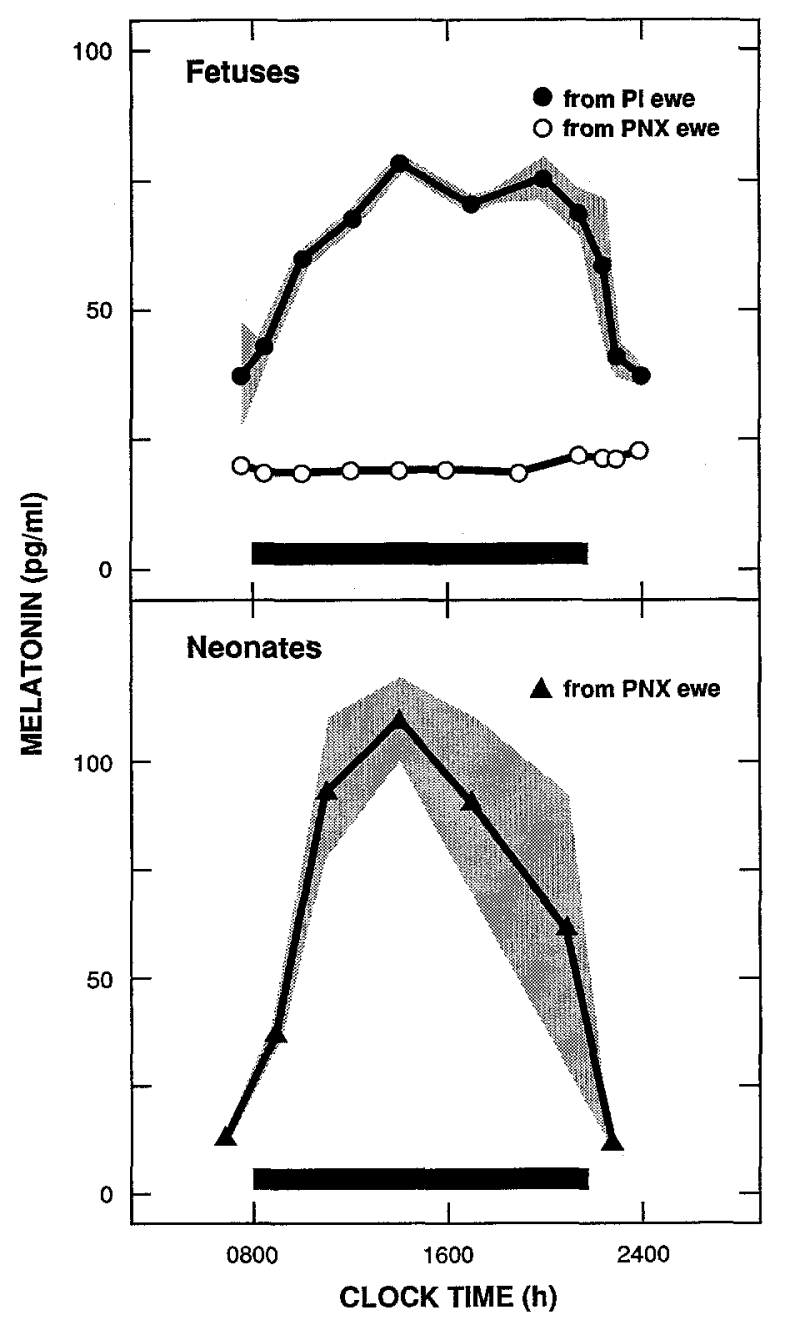

Fig. 5. Pattern of plasma melatonin in circulation over $24 \mathrm{~h}$ in the fetus during the last third of gestation and in the newborn lamb. Data are the mean concentrations of melatonin. Shaded area represents the standard error, the absence of shading indicates that the variance was encompassed by the area of the symbol. Top: Fetal sheep from pineal-intact (PI) ewes (eighteen 24-h periods in six fetuses) and from pinealectomized (PNX) ewes (twenty-four 24-h periods in six fetuses); Bottom: Neonatal lambs $(n=3)$ at 5 days of age from pinealectomized ewes (three 24-h periods). Dark bar indicates night portion of the photoperiod ( $10 \mathrm{~h}$ of light each day). (Modified from Yellon and Longo, 1988).

Although the fetal pineal gland may synthesize melatonin before birth (Kennaway et al., 1977; McMillen et al., 1989), the nocturnal rise in circulating melatonin in the fetus is likely to reflect the pattern of melatonin secreted from the maternal pineal gland. In fact, melatonin readily crosses the placenta 
(Kennaway et al., 1977, 1981; Yellon and Longo, 1988; Zemdegs et al., 1988), and pinealectomy of the pregnant ewe abolishes the melatonin rhythm in fetal circulation (Fig. 5, top) (Yellon and Longo, 1988; McMillen and Nowak, 1989). Therefore, the fetal lamb is exposed to an unambiguous pattern of circulating melatonin which reflects the photoperiod cues perceived by the mother.

Soon after birth, lambs are capable of generating a circadian melatonin rhythm (Fig. 5, bottom). In lambs born to pinealectomized ewes, the duration of the nocturnal melatonin rise is appropriate for the prevailing photoperiod within the first week of life (Yellon and Longo, 1988), a finding similar to that in most lambs from pineal-intact ewes (Claypool et al., 1989). By 7 weeks of age, the lamb is able to generate and entrain its melatonin rhythm to postnatal changes in photoperiod (Wood et al., 1989; Nowak et al., 1990).

\section{ONTOGENY OF RESPONSIVENESS TO PHOTOPERIOD AND MELATONIN}

Of equal importance to the maturation of the melatonin rhythm is the development of responsiveness to melatonin. Changes in prolactin secretion conveniently serve as a physiological indication of photoperiod responsiveness because in adult ruminants, prolactin concentrations are increased by long days and decreased by short days (Lincoln et al., 1978; Plotka et al., 1982; Mori and Okamura, 1986; Critser et al., 1987b; Poulton et al., 1987). For the lamb, just as photoperiod entrains the nocturnal melatonin rhythm within 7 weeks after birth, exposure to long or short days increases or decreases, respectively, the concentration of prolactin in circulation (Ebling et al., 1988; Forbes et al., 1975). This prolactin response to photoperiod is directly mediated by the lamb's own melatonin rhythm because pineal denervation, which eliminates physiologic cues about day length, blocks the increase in serum prolactin following neonatal exposure to long days (Ebling et al., 1988).

Responsiveness of prolactin secretion to photoperiod in the neonatal lamb is dependent upon postnatal ontogeny of the melatonin rhythm. However, the fetus also appears to be able to recognize changes in day length (Bassett et al., 1988,1989 ). At birth, prolactin concentrations were higher in newborn lambs from ewes maintained in long days $(16 \mathrm{~L}$, i.e. $16 \mathrm{~h}$ of light each day) compared with short $(8 \mathrm{~L}$ ) days during the final third of gestation (Ebling et al., 1989). Moreover, transfer of these lambs on the day of birth from long or short days to intermediate photoperiod of $12 \mathrm{~L}$ suppressed or stimulated, respectively, prolactin secretion within 3 weeks. Such findings suggest that the lamb has already developed the capability to recognize photoperiod information in utero, well before postnatal maturation of the circadian melatonin rhythm. Prenatal recognition of photoperiod information is not unique to 
sheep because in two species of rodents reproductive development at puberty is dependent upon prenatal photoperiod history (Horton, 1984; Stetson et al., 1986). In addition, newborn red deer stag calves have high prolactin levels during summer, but within 2-3 months of age, concentrations fall in direct relation to the decreasing day lengths of autumn (Suttie and Kay, 1985). As plasma prolactin in neonatal lambs is regulated by photoperiod and melatonin (Ebling et al., 1988), circumstantial evidence suggests that this may also be true for the deer. Therefore, a photoperiodic history begins before birth in a variety of mammals, and serves as a reference for the postnatal photoperiod cues which ultimately determine the onset of reproductive function.

If recognition of photoperiod begins in utero in sheep, then exposure of the neonate to the proper sequence of long and short days might be expected to advance the age at puberty. However, studies reveal that exposure to long days during the early postnatal period and short days thereafter, actually delay the onset of reproductive cycles (Yellon and Foster, 1985; Foster et al., 1986). Attempts to fulfill the long-day requirement before 15 weeks of age were unable to produce repetitive ovulatory cycles in most lambs. Therefore, these effects of photoperiod suggest that the mechanism driving development of reproductive function is distinct from the mechanism that regulates secretion of prolactin and the circadian melatonin rhythm.

Ultimately, the ability of photoperiod to influence reproductive development depends on the capability for day length to influence gonadotrophin secretion. As already mentioned, increased frequency of pulsatile LH secretion and reduced sensitivity to estrogen feedback underlie reproductive development. Recent evidence suggests that photoperiod modulates pulsatile LH secretion in ovariectomized lambs within 6 weeks after birth (Ebling and Foster, 1990). However, these lambs were highly sensitive to steroid feedback because estradiol was able to suppress $\mathrm{LH}$ secretion irrespective of photoperiod. The significance of the findings that day-length information can influence the reproductive axis in young lambs has yet to be realized. Evidence points to a maturational change in a steroid-dependent mechanism later in development (described for the adult ewe below), as important for puberty in sheep (Foster, 1988).

In adult sheep, photoperiod and melatonin are recognized as modulators of the $\mathrm{GnRH}$ pulse generator and the $\mathrm{LH}$ response to estrogen negative feedback (see review by Karsch et al., 1984, pp. 196-199). In sheep, pulsatile LH secretion is directly related to the duration of night such that LH pulse frequency is increased by short days and decreased by long days. The onset of breeding is also associated with a reduced feedback sensitivity to estrogen. Experimentally, it has been shown that estradiol implants, which suppress LH secretion in long days, typical of anestrus, are unable to restrain LH release; subsequently LH concentrations increase in circulation in coincidence 
with the onset of reproductive activity. These effects of photoperiod on LH secretion and the negative feedback potency of estrogen are mimicked by timed infusions of melatonin in pinealectomized ewes (Bittman et al., 1985). The duration of daily infusions of melatonin was directly related to LH pulse frequency and the LH response to estradiol negative feedback.

In another seasonal ruminant, the goat, the relationship between pulsatile LH secretion, estrogen feedback and day length is, in general, comparable to findings in the ewe (Mori et al., 1987; Chemineau et al., 1988). Long days reduce LH pulse frequency and enhance the potency of estradiol negative feedback. Reversal of these long-day effects by timed melatonin treatment (Chemineau et al., 1988), support the contention that duration of melatonin secretion is similarly involved in the control of the $\mathrm{GnRH}$ pulse generator in goats and sheep. In contrast to these ruminants, cattle are not considered seasonal breeders. However, in young female cows photoperiod influences the onset of puberty (Critser et al., 1983) and the feedback response of LH to estradiol (Critser et al., 1987a,b). Further information is lacking about the reproductive effects of melatonin and the role of the pineal gland in bovine physiology.

\section{GROWTH, PHOTOPERIOD AND REPRODUCTIVE DEVELOPMENT}

Growth and the attainment of a critical body size are important for puberty and are not just considerations when disease or insufficient nutrition delay maturation of reproductive function (Foster, 1980; Foster et al., 1985). Growth must be adequate in the lamb for puberty to occur during the first autumn after birth (Foster et al., 1985, 1986). The deer does not typically achieve a body size or level of growth for reproductive function until the second year of life (Kelly and Moore, 1978; Suttie, 1981). Puberty in deer occurs during the second autumn when photoperiod cues are again appropriate for onset of breeding. Evidence in both species indicate that reproductive development is blocked when growth-related cues are absent even when photoperiod history is appropriate for normal puberty.

Consideration of growth and photoperiod requirements for puberty helps explain delayed puberty in lambs that by chronological age should have begun reproductive function. The failure to achieve normal growth may account for delayed puberty in lambs that experienced the alternate sequence of long days and then short days at an early age (Foster, 1981; Yellon and Foster, 1985). A similar statement can be made about deer during the first year of life or in nutritionally restricted animals; photoperiod history may have been appropriate but body size or growth cues were not. As already discussed, photoperiod cues are probably recognized in sheep and deer from an early age, but by the normal age for puberty, an appropriate body size had not been achieved in time to sustain reproductive function. Even in growth-retarded lambs with 
delayed puberty, photoperiod time measurements is maintained (Foster and Yellon, 1985). Nutritionally restricted lambs were transferred from natural short days to artificial photoperiod, either long days (15L) or short days (9L). Six weeks later the lambs in long days were shifted to short days and the level of nutrition increased in both groups to induce rapid growth. Only the group that experienced long days increased secretion of LH in a manner typical of a sexually mature response. Therefore, evidence suggests that a photoperiod history is maintained in lambs at a small physiologic size, whether prepubertal or growth retarded.

Given the influence of growth and photoperiod on reproductive development, there is also a known association of photoperiod on growth. Body weight gain is increased in long days compared with short days in the lamb (Schanbacher and Crouse, 1981), as well as in prepubertal and adult red deer (Suttie et al., 1984). However, increased live-weight gain may not necessarily be associated with carcass composition changes (Tucker et al., 1984). Moreover, in the white-tailed deer, short days promote fat accretion (Abbott et al., 1984). In the lamb, growth-promoting effects of long days may be attributed to increased appetite (Schanbacher et al., 1982; Simpson et al., 1984) but probably reflect a general alteration in metabolism (Tucker et al., 1984), since they are also present in nutritionally restricted prepubertal sheep (Forbes et al., 1975 ) and cattle (Petitclerc et al., 1983). It is most likely that there are longterm rhythms of metabolism, appetite and growth potential, and that these are all interrelated. In addition, photoperiod may synchronize these rhythms although the way in which it does so and indeed the extent to which these rhythms are related is unknown. Finally, these effects of photoperiod on growth are likely to be mediated by the pattern of melatonin in circulation. Melatonin treatments predictably affect weight gain or loss in deer (Webster and Barrell, 1985), and Djungarian hamsters (Elliot et al., 1989). Therefore, the pineal melatonin rhythm may have an important contribution in growth and metabolism in developing ruminants and thus, in turn, may provide sizerelated cues for puberty. Whether melatonin rhythms signal to the growth axis in precisely the same way as they do to the reproductive axis is intriguing, but conceptually this need not be so.

\section{CONCLUSIONS}

Considerable understanding of the importance of photoperiod in the process of reproductive development has been provided by studies in domestic ruminants. The female lamb has served well as a model to reveal that photoperiod during development is a cue for the normal onset of reproductive function at puberty. Information about photoperiod is mediated by the neural control of pineal gland production of the hormone melatonin. The daily pattern of melatonin in circulation relays information about both time of day, to 
distinguish day from night, and day length, to provide a reference for the season. In terms of its effects on reproduction, environmental photoperiod may be considered synonymous with the circadian melatonin rhythm.

At present, melatonin is the only known hormone whose physiological function is known to depend on its circadian pattern in circulation. What is special about the role of melatonin for reproduction is that the melatonin rhythm is a physiologic signal communicating information about time. As the hands of a biological clock, the circadian melatonin rhythm is referenced each day and remembered as part of a history to influence a variety of physiological systems. Although evidence supports the duration of the melatonin rhythm as the key component for mediating information about day length, the neuroendocrine mechanisms of puberty appear to depend on the internal coincidence of at least two important cues, those concerning the photoperiod, hence melatonin, and those involving growth.

For reproductive development, ontogeny of the circadian melatonin rhythm occurs neonatally and serves several important functions. The melatonin rhythm continues to provide information about time of day to the postnatal lamb that was initially furnished in utero by the ewe. Maturation of the pineal melatonin pattern is an index of neuroendocrine development, and those brain mechanisms generating circadian rhythms. Finally, the significance of precise time measurement in lambs are, at least to improve adaptation of the newborn to environmental conditions, and to synchronize the onset of breeding activity, a mechanism which ultimately ensures the opportunity for individuals to reproduce during their first mating season.

\section{ACKNOWLEDGMENTS}

We appreciate the secretarial and editorial work of Sheila Whitson in preparation of the manuscript, and thank Tovaghgol E. Adel for assistance with graphics. This work was supported by grants from the NIH (HD 22479, HD 03807, HD 07048, HD 18258, HD 18394) and a Loma Linda University Pediatric Department Research grant.

\section{REFERENCES}

Abbott, M.J., Ullrey, D.E., Ku, P.K., Schmitt, S.M., Romsos, D.R. and Tucker, H.A., 1984. Effect of photoperiod on growth and fat secretion in white-tailed doe fawns. J. Wildl. Manage., 48: 776-787.

Bartness, T.J. and Goldman, B.D., 1989. Mammalian pineal melatonin: a clock for all seasons. Experientia, 45: 939-945.

Bassett, J.M., Bomford, J. and Mott, J.C., 1988. Photoperiod: An important regulator of plasma prolactin concentration in fetal lambs during late gesatation. Q. J. Exp. Physiol., 73: 241244. 
Bassett, J.M., Curtis, N., Hanson, N. and Weeding, C.M., 1989. Effects of altered photoperiod or maternal melatonin administration on plasma prolactin concentrations in fetal lambs. J. Endocrinol., 122: 633-643.

Bissonnette, T.H., 1941. Experimental modification of breeding cycles in goats. Physiol. Zool., 14: 379-383.

Bittman, E.L. and Karsch, F.J., 1984. Nightly duration of pineal melatonin secretion determines the reproductive response to inhibitory day lengths in the ewe. Biol. Reprod., 30: 585593.

Bittman, E.L., Kaynard, A., Olster, D.H., Robinson, J., Yellon, S.M. and Karsch, F.J., 1985. Pineal melatonin mediates the photoperiodic control of pulsatile luteinizing hormone secretion in the ewe. Neuroendocrinology, 40: 409-418.

Bubenik, U.A. and Smith, P.S., 1987. Circadian and circannual rhythms of melatonin in plasma of male white tailed deer and the effect of oral administration of melatonin. J. Exp. Zool., 241: 81-88.

Buttle, H.L., 1977. The effect of anterior cervical ganglionectomy on the seasonal variation in prolactin concentration in goats. Neuroendocrinology, 23: 121-128.

Chemineau, P., Martin, G.B., Saumande, J. and Normant, E., 1988. Seasonal and hormonal control of pulsatile LH secretion in the dairy goat (Capra lircus). J. Reprod. Fertil., 83: 9198.

Claypool, L.E. and Foster, D.L., 1990. Sexual differentiation of the mechanism controlling pulsatile secretion of luteinizing hormone contribute sexual differences in the timing of puberty in sheep. Endocrinology, 126: 1206-1215.

Claypool, L.E., Wood, R.I., Yellon, S.M. and Foster, D.L., 1989. The ontogeny of the melatonin rhythm in the sheep. Endocrinology, 124: 2135-2143.

Critser, J.K., Miller, K.F., Gunsett, F.C. and Grather, O.J., 1983. Seasonal LH profile in ovariectomized cattle. Theriogenology, 19: 181-191.

Critser, J.K., Block, T.M., Folkman, G. and Hansen, E.R., 1987a. Effect of photoperiod on LH, FSH, prolactin and melatonin patterns in ovariectomized prepubertal heifers. J. Reprod. Fertil., 81: 29-39.

Critser, J.K., Lindstrom, M.J., Hinshelwood, M.M. and Hauser, E.R., 1987b. Effect of photoperiod on LH, FSH and prolactin patterns in ovariectomized oestradiol-treated heifers. J. Reprod. Fertil., 79: 599-608.

Ebling, F.J.P. and Foster, D.L., 1989. Pineal melatonin rhythms and the timing of puberty in mammals. Experientia, 45: 946-954.

Ebling, F.J.P., Claypool, L.E. and Foster, D.L., 1988. Neuroendocrine responsiveness to light during the neonatal period in sheep. J. Endocrinol., 119: 211-218.

Ebling, F.J.P., Wood, R.I., Suttie, J.M., Adel, T.E. and Foster, D.L., 1989. Prenatal photoperiod influences neonatal prolactin secretion in sheep. Endocrinology, 125: 384-391.

Ebling, F.J.P., Kushler, R.H. and Foster, D.L., 1990. Pulsatile LH secretion during sexual maturation in the female sheep: photoperiodic regulation in the presence and absence of ovarian steroid feedback as determined in the same individual. Neuroendocrinology, 52: 229237.

Elliott, J.A., Bartness, T.J. and Goldman, B.D., 1989. Effect of melatonin infusion duration and frequency on gonad, lipid, and body mass in pinealectomized male Siberian hamsters. J. Biol. Rhythms, 4: 439-455.

Forbes, J.M., Driver, P.M., El Shahat, A.A., Bosz, T.G. and Scanes, C.G., 1975. The effect of daylength and level of feeding on serum prolactin in growing lambs. J. Endocrinol., 64: 549554.

Foster, D.L., 1980. Comparative development of mammalian females: proposed analogies among patterns of LH secretion in various species. In: C. La Cauza and A.W. Root (Editors), Problems in Pediatric Endocrinology. Academic Press, London, pp. 193-210. 
Foster, D.L., 1981. Mechanism for delay of first ovulation in lambs born in the wrong season (fall). Biol. Reprod., 25: 85-92.

Foster, D.L., 1988. Puberty in the female sheep. In: E. Knobil and J.D. Neill (Editors), The Physiology of Reproduction. Raven Press, New York, pp. 1739-1762.

Foster, D.L. and Ryan, K.D., 1981. Endocrine mechanisms governing transition into adulthood in female sheep. J. Reprod. Fertil., 30 (Suppl.): 75-90.

Foster, D.L. and Yellon, S.M., 1985. Photoperiodic time measurement is maintained in undernourished lambs with delayed puberty. J. Reprod. Fertil., 75: 203-208.

Foster, D.L., Yellon, S.M. and Olster, D.H., 1985. Internal and external determinants of the timing of puberty in the female. J. Reprod. Fertil., 75: 327-344.

Foster, D.L., Karsch, F.J., Olster, D.H., Ryan, R.K. and Yellon, S.M., 1986. Determinants of puberty in a seasonal breeder. Recent Prog. Horm. Res., 42: 330-384.

Foster, D.L., Ebling, F.J.P. and Claypool, L.E., 1988a. Timing of puberty by photoperiod. Reprod. Nutr. Dev., 28: 349-364.

Foster, D.L., Ebling, F.J.P., Claypool, L.E. and Woodfill, C.J.I., 1988b. Cessation of long day melatonin rhythms time puberty in a short day breeder. Endocrinology, 123: 1636-1641.

Foster, D.L., Yellon, S.M., Ebling, F.J.P. and Claypool, L.E., 1988c. Are ambient short-day cues necessary for puberty in a short-day breeder? Biol. Reprod., 38: 821-829.

Foster, D.L. Ebling, F.J.P., Claypool, L.E., Wood, R.I., Adel, and Schramm, T.E., 1989. Amplitude modulation of the nightly melatonin rise in the neonatal lamb and subsequent timing of puberty. Biol. Reprod., 40: 920-928.

Goldman, B.D., Darrow, J.M. and Yogev, L., 1984. Effects of timed melatonin infusions on reproductive development in the Djungarian hamster (Phodopus sungorus). Endocrinology, 114: 2076-2083.

Hafez, E.S.E., 1952. Studies on the breeding season and reproduction of the ewe: 1 . The breeding season in different environments. 2 . The breeding season in one locality. J. Agric. Sci., 42: $189-265$.

Hansen, P.J., 1985. Photoperiodic regulation of reproduction in mammals breeding under long days versus mammals breeding under short days. Anim. Reprod. Sci., 9: 301-315.

Hastings, M.H., Vance, G. and Maywood, E., 1989. Some reflections on the phylogeny and function of the pineal. Experientia, 45: 903-1008.

Horton, T.H., 1984. Growth and reproductive development of male Microtus montanus is affected by the prenatal photoperiod. Biol. Reprod., 31: 499-504.

Karsch, F.J., Bittman, E.L., Foster, D.L., Goodman, R.L., Legan, S.J. and Robinson, J.E., 1984. Neuroendocrine basis of seasonal reproduction. Recent Prog. Horm. Res., 40: 185-232.

Kelly, R.W. and Moore, G.M., 1978. Reproductive performance in farmed red deer. In: K.R. Drew (Editor), Advances in Deer Farming. Editorial Services, Wellington, pp. 16-18.

Kennaway, D.J., 1984. Pineal function in ungulates. Pineal Res. Rev., 2: 113-140.

Kennaway, D.J. and Gilmore, T.A., 1984. Effects of melatonin implants in ewe lambs. J. Reprod. Fertil., 70: 39-45.

Kennaway, D.J. and Gilmore, T.A., 1985. Effects of melatonin implants in ram lambs. J. Reprod. Fertil., 73: 85-91.

Kennaway, D.J., Matthews, C.D., Seamark, R.F., Phillipou, G. and Schilthuis, M., 1977. On the presence of melatonin in pineal glands and plasma of foetal sheep. J. Steroid Biochem., 8: 559-563.

Kennaway, D.J., Matthews, C.D. and Seamark, R.F., 1981. Pineal function of pregnancy: Studies in sheep and man. In: C.D. Seamark and R.F. Matthews (Editors), Pineal Function. Elsevier/North Holland Biomedical Press, New York, pp. 123-136.

Kennaway, D.J., Gilmore, T.A. and Dunstan, E.A., 1985. Pinealectomy delays puberty in ewe lambs. J. Reprod. Fertil., 74: 119-125. 
Legan, S.J. and Winans, S.S., 1981. The photoneuroendocrine control of seasonal breeding in the ewe. Gen. Comp. Endocrinol., 45: 317-328.

Lincoln, G.A., McNeilly, A.S. and Cameron, C.L., 1978. The effects of a sudden decrease or increase in daylength on prolactin secretion in the ram. J. Reprod. Fertil., 52: 305-311.

Maeda, R.I., Mori, Y, and Kano, Y., 1988. Involvement of melatonin in the seasonal changes of the gonadal function and prolactin secretion in female goats. Reprod. Nutr. Dev., 20:487497.

McMillen, I.C. and Nowak, R., 1989. Maternal pinealectomy abolishes the diurnal rhythm in plasma melatonin concentrations in the fetal sheep and pregnant ewe during late gestation. J. Endocrinol., 120: 459-464.

McMillen, I.C., Parkington, H.C. and McCance, I., 1989. Effect of isoprenaline on the output of melatonin from the fetal and newborn pineal gland in vitro. Acta Endocrinol. (Copenhagen ), 121: 770-776.

Mori, Y. and Okamura, H., 1986. Effects of timed melatonin infusion on prolactin secretion in pineal denervated goat. J. Pineal Res., 3: 77-86.

Mori, Y., Maeda, K., Sawasaki, T. and Kano, Y., 1984. Effect of long days and short days on estrous cyclicity in two breeds of goats with different seasonality. Jpn. J. Anim. Reprod., 30: 239-245.

Mori, Y., Tanaka, K., Maeda, K., Hoshino, R. and Kano, Y., 1987. Photoperiodic modification of negative and positive feedback effects of estradiol on LH secretion in ovariectomized goats. J. Reprod. Fertil., 80: 523-529.

Namboodiri, M.A.A., Sugden, D., Klein, D.C., Tamarkin, L. and Medford, I.N., 1985. Serum melatonin and pineal indoleamine metabolism in a species with a small day/night $\mathrm{N}$-acetyl transferase rhythm. Comp. Biochem. Physiol., 80B: 731-736.

Nowak, R. and Rodway, R.G., 1985. Effect of intravaginal implants of melatonin on the onset of ovarian activity in adult and prepubertal ewes. J. Reprod. Fertil., 74: 287-293.

Nowak, R., Young, I.R. and McMillen, I.C., 1990. Emergence of the diurnal rhythm in plasma melatonin in newborn lambs delivered to intact or pinealectomized ewes. J. Endocrinol., 125: 97-102.

Oldham, C.M. and Gray, S.J., 1984. The "ram effect" will advance puberty in 9-10 month old Merino ewes independent of their season of birth. Proc. Aust. Soc. Anim. Prod., 15: 727728.

Ortavant, R., Pelletier, J., Ravault, J.P., Thimonier, J. and Volland-Nail, P., 1985. Photoperiod: mass-proximal and distal factor of the circannual cycle of reproduction in farm mammals. Oxf. Rev. Reprod. Biol., 7: 305-345.

Petitclerc, D., Chapin, L.T., Emery, R.S. and Tucker, H.A., 1983. Body growth, growth hormone, prolactin and puberty reponse to photoperiod and plane of nutrition in Holstein heifers. J. Anim. Sci., 57: 892-898.

Plotka, E.D., Seal, V.S. and Verme, L.J., 1982. Morphologic and metabolic consequences of pinealectomy in deer. In: R.J. Reiter (Editor), The Pineal Gland. Vol. III: Extra-reproductive Effects. CRC Press Inc., Boca Raton, FL, pp. 153-169.

Poulton, A.L., English, J., Symons, A.M. and Arendt, J., 1987. Changes in plasma concentrations of LH, FSH and prolactin in ewes receiving melatonin and short-photoperiod treatments to induce early onset of breeding activity. J. Endocrinol., 112: 103-111.

Reiter, R.J., 1986. The pineal gland and pubertal development in mammals: A state of the art assessment. In: D. Gupta and R.J. Reiter (Editors), The Pineal Gland During Development: From Fetus to Adult. Croom Helm, London, pp. 100-116.

Robinson, J.E. and Karsch, F.J., 1987. Photoperiodic history and a changing melatonin pattern can determine the neuroendocrine response of the ewe to daylength. J. Reprod. Fertil., 80: 159-165. 
Rollag, M.D. and Niswender, G.D., 1976. Radioimmunoassay of serum concentration of melatonin in sheep exposed to different lighting regimes. Endocrinology, 98: 482-488.

Rusak, B. and Zucker, I., 1979. Neural regulation of circadian rhythms. Physiol. Rev., 59: 449526.

Schanbacher, B.D. and Crouse, J.D., 1981. Photoperiodic regulation of growth: a photosensitive phase during light. Am. J. Physiol., 241: E1-E5.

Schanbacher, B.D. and Crouse, J.D., 1980. Growth and performance of growing-finishing lambs exposed to long or short photoperiods. J. Anim. Sci., 51: 943-948.

Schanbacher, B.D., Hahn, G.L. and Nienaber, J.A., 1982. Effects of contrasting photoperiods and temperatures on performance traits of confinement-reared ewe lambs. J. Anim. Sci., 55: 620-626.

Schwartz, W.B., Davidson, L.C. and Smith, C.B., 1980. In vivo metabolic activity of a putative circadian oscillator, the rat suprachiasmatic nucleus. J. Comp. Neurol., 189: 157-167.

Simpson, A.J., Suttie, J.M. and Kay, R.N.B., 1984. The influence of artificial photoperiod on the growth, appetite and reproductive status of male red deer and sheep. Anim. Reprod. Sci., 6: 292-299.

Stetson, M.H., Elliott, J.A. and Goldman, B.D., 1986. Maternal transfer of photoperiodic information influences the photoperiodic response of prepubertal Djungarian hamsters. Biol. Reprod., 34: 664-669.

Sugden, D., 1989. Melatonin biosynthesis in the mammalian pineal gland. Experientia, 45: 922932.

Suttie, J.M., 1981. The influence of nutrition and photoperiod on the growth, development and endocrine status of captive red deer and Soay rams. Ph.D. Thesis, University of Aberdeen.

Suttie, J.M. and Kay, R.N.B., 1985. Influence of plane of winter nutrition on plasma concentrations of prolactin and testosterone and their association with voluntary food intake in red deer stags (Cervus elaphus). Anim. Reprod. Sci., 8: 247-258.

Suttie, J.M., Corson, I.D. and Fennessy, P.F., 1984. Voluntary intake, testis development and antler growth patterns of male red deer under a manipulated photoperiod. Proc. NZ Soc. Anim. Prod., 44: 167-170.

Tucker, H.A., Petitclerc, D. and Zinn, S.A., 1984. The influence of photoperiod on body weight gain, body composition, nutrient intake and hormone secretion. J. Anim. Sci., 59: 16101620 .

Wayne, N.L., Malpaux, B. and Karsch, F.J., 1988. How does melatonin code for daylength: duration of nocturnal melatonin release or coincidence of melatonin with a light entrained sensitive period? Biol. Reprod., 39: 66-75.

Webster, J.R. and Barrell, G.K., 1985. Advancement of reproductive activity, seasonal reduction in prolactin secretion and seasonal pelage changes in pubertal red deer hinds (Cervus elaphus) subject to artificially shortened daily photoperiod or daily melatonin treatments. J. Reprod. Fertil., 73: 255-260.

Wood, R.I., Claypool, L.E., Ebling, F.J.P. and Foster, D.L., 1989. Entrainment of the melatonin rhythms in early postnatal lambs and their mothers. J. Biol. Rhythms, 4: 457-465.

Wood, R.I., Ebling, F.J.P., I'Anson, H. and Foster, D.L., 1991. The timing of neuroendocrine puberty in the male lamb by photoperiod. Biol. Reprod., 45: 82-88.

Yellon, S.M. and Foster, D.L., 1985. Alternate photoperiods time puberty in the female lamb. Endocrinology, 116: 2090-2097.

Yellon, S.M. and Foster, D.L., 1986. Melatonin rhythms time photoperiod-induced puberty in the female lamb. Endocrinology, 119: 44-49.

Yellon, S.M. and Goldman, B.D., 1984. Photoperiod control of reproductive development in the male Djungarian hamster (Phodopus sungorus). Endocrinology, 114: 664-670.

Yellon, S.M. and Longo, L.D., 1987. Melatonin rhythms in fetal and maternal circulation during pregnancy in sheep. Am. J. Physiol., 252: E799-E802. 
Yellon, S.M. and Longo, L.D., 1988. Effect of maternal pinealectomy and reverse photoperiod on the circadian melatonin rhythm in the sheep and fetus during the last trimester of pregnancy. Biol. Reprod., 39: 1093-1099.

Yellon, S.M., Tamarkin, L., Pratt, B.L. and Goldman, B.D., 1982. Pineal melatonin in the Djungarian hamster: photoperiodic regulation of a circadian rhythm. Endocrinology, 111: 488-492.

Yellon, S.M., Tamarkin, L. and Goldman, B.D., 1985a. Maturation of the pineal melatonin rhythm in long- and short-day reared Djungarian hamsters. Experientia, 41: 651-652.

Yellon, S.M., Bittman, E.L., Lehman, M.N., Olster, D.H., Robinson, J.E. and Karsch, F.J., 1985b. Importance of duration of nocturnal melatonin secretion in determining the reproductive response to inductive photoperiod in the ewe. Biol. Reprod., 32: 523-529.

Zemdegs, I.Z., McMillen, I.C., Walker, D.W., Thorburn, G.D. and Nowak, R., 1988. Diurnal rhythms in plasma melatonin concentrations in the fetal sheep and and pregnant ewe during late gestation. Endocrinology, 123: 284-289. 